\title{
Gabapentin enacarbil for antipsychotic induced akathisia in schizophrenia patients: a pilot open-labeled study
}

This article was published in the following Dove Press journal:

Neuropsychiatric Disease and Treatment

\author{
Masahiro Takeshima' \\ Hiroyasu Ishikawa ${ }^{2}$ \\ Takashi Kanbayashi' \\ Tetsuo Shimizu ${ }^{3}$ \\ 'Department of Neuropsychiatry, \\ Akita University Graduate School \\ of Medicine, Akita City, Akita \\ 0I0-8543, Japan; ${ }^{2}$ Department \\ of Neuropsychiatry, Nakadori \\ Rehabilitation Hospital, Akita \\ City, Akita 01 0-000I, Japan; ${ }^{3}$ Akita \\ Prefectural Mental Health and \\ Welfare Center, Akita City, Akita \\ 0I0-000I, Japan
}

Objective: Gabapentin and its prodrug are candidate therapeutic agents for akathisia. An open-label pilot study was conducted to investigate the therapeutic potential of gabapentin enacarbil (GE) for akathisia.

Methods: In an open-labeled investigator-initiated clinical trial, nine outpatients with antipsychotics-induced akathisia were administered GE (300 or $600 \mathrm{mg} / \mathrm{day}$ ) over 2 weeks. The BARS global akathisia score was used to assess akathisia. The BPRS was used to assess psychiatric symptoms. The subjects were also systematically questioned regarding the adverse events described in an interview form following GE treatment. An intension-to-treat analysis including all patients enrolled in the present study was completed.

Results: One patient declined to participate further in the study on the third day after the start of treatment. Eight patients thus completed the entire trial (male: 2, female: 6, age [mean $\pm \mathrm{SD}$ ]: $38.8 \pm 11.6$ years). The average dosage of GE was $567 \mathrm{mg} /$ day $(300 \mathrm{mg} /$ day $[\mathrm{n}=1], 600 \mathrm{mg} /$ day $[\mathrm{n}=8])$. The BARS global akathisia score significantly decreased after 1 and 2 weeks of treatment when compared to baseline ( $P=0.01$ and $P=0.01$, respectively). There were no significant differences in BPRS score 1 or 2 weeks after the start of treatment. No serious adverse events occurred.

Conclusion: GE has therapeutic potential for antipsychotics-induced akathisia. No additional risk of GE use for the management of akathisia was indicated.

Keywords: clinical trial, antipsychotic agents, restless legs syndrome, schizophrenia

\section{Introduction}

Akathisia, one of the major side effects of antipsychotics, ${ }^{1}$ should be treated early, as it is associated with suicidality, ${ }^{2}$ exacerbation of psychotic symptoms, ${ }^{3}$ poorer treatment outcome, ${ }^{4}$ non-compliance with antipsychotic treatment, ${ }^{5}$ and reduced well-being in patients with schizophrenia. ${ }^{6}$ The Maudsley Prescribing Guidelines recommend the reduction/cessation of drugs causing akathisia as a first step and the use of antipsychotic drugs that are less likely to cause akathisia, such as quetiapine and clozapine (CLZ), ${ }^{7}$ as a second step. However, in practice, it is often difficult to reduce the dose of or change the type of antipsychotics in patients with schizophrenia, as indicated in the guideline. Although propranolol is the first-line drug in the guidelines, the response rate of this drug is as low as $30.0 \%$ and the discontinuation rate is as high as $16.7 \%{ }^{8}$ Asthma as a contraindication of the drug is also a problem in clinical practice because its prevalence in schizophrenia patients is up to $10 \% .{ }^{9}$ Therefore, new akathisia drug therapies are required.
Correspondence: Masahiro Takeshima Department of Neuropsychiatry, Akita University Graduate School of Medicine, I-I-I Hondo, Akita City, Akita 010-8543, Japan

Tel $+81 \quad 188846122$

Fax +81188846445

Email m.takeshima@med.akita-u.ac.jp 
Gabapentin and its prodrug are candidate therapeutic agents for akathisia. ${ }^{10-12}$ The case of a single patient whose akathisia symptoms decreased after gabapentin use was first reported by Pfeffer et al. ${ }^{10}$ Another successful case of gabapentin use for the treatment of akathisia was reported by Sullivan and Wilbur. ${ }^{11}$ In a previous case study, the authors also reported the therapeutic potential of gabapentin enacarbil (GE), a prodrug of gabapentin, for akathisia. ${ }^{12}$ Although gabapentin and its prodrug have therapeutic potential, all previous reports of its use for the treatment of akathisia describe studies with one or two cases. In addition, reduced central $\gamma$-aminobutyric acid (GABA)-ergic activity is suggested as a pathogenic mechanism for akathisia. ${ }^{13}$ Because gabapentin increases GABA activity, ${ }^{14,15}$ this drug and its prodrug have a potential to attenuate akathisia symptoms. The authors have, therefore, conducted an open-label pilot study to investigate the effectiveness of GE for akathisia.

\section{Patients and methods Subjects}

This study was a 2-week long, open-labeled, prospective pilot trial. The subjects were nine outpatients at the Departments of Neuropsychiatry at Akita University Hospital and Yuri Kumiai General Hospital with antipsychotics-induced akathisia. Akathisia was diagnosed based on the DSM-5 criteria. ${ }^{16}$ This study was conducted from September 2016 to July 2018. The exclusion criteria were 1) age $<20$ years; 2) pregnancy or lactation; 3 ) additional use of other drugs with therapeutic potential for akathisia ( $\beta$-blockers, benzodiazepines, anticholinergic agents, gabapentin, or GE) within 2 weeks of starting this study; 4) having suicidal ideas; 5) severe renal failure; 6) having a past history of restless leg syndrome; and 7) severe akathisia with the maximum BARS score. ${ }^{17}$ These criteria were applied at the time of research recruitment.

\section{Treatment protocol}

Eligible subjects were administered GE (300 or $600 \mathrm{mg} /$ day) for 2 weeks while continuing to use the antipsychotics that caused akathisia. During the study period, no akathisia medication ( $\beta$-blockers, benzodiazepines, or anticholinergic drugs) was used in addition to GE. The primary endpoint was the BARS global akathisia score (range: 0-5). The subjects were assessed for the severity of akathisia at baseline and after 1 and 2 weeks of treatment. Patients whose BARS global akathisia scores were higher at week 1 than at baseline were dropped from the study at that time. The BARS Objective akathisia score, BARS Subjective akathisia score (Awareness of restlessness and Distress related to restlessness), and BPRS scores were examined at baseline and after 1 and 2 weeks of treatment as secondary measures. ${ }^{18}$ The subjects were also systematically questioned regarding the following adverse events in an interview after GE treatment: ${ }^{19}$ somnolence, sedation, abnormal dreams, insomnia, irritability, depressed mood, anxiety, illusion, disorientation, disturbance in attention, decreased libido, nausea, constipation, diarrhea, weight gain, weight loss, abdominal pain, vomiting, abdominal discomfort, dyspepsia, gastroesophageal reflux disease, flatulence, increased appetite, tremor, balance disorder, ataxia, dysarthria, dizziness, vertigo, fatigue, headache, palpitation, dry mouth, dysgeusia, paresthesia, feeling abnormal, feeling drunk, pain in extremity, myalgia, arthralgia, muscle spasm, peripheral edema, malaise, asthenia, back pain, rash, pruritus, and blurred vision. During the study period, clinical evaluation of the participants was performed by a single evaluator.

\section{Ethics approval and informed consent}

This study was conducted in accordance with the Declaration of Helsinki. This study was approved by the Ethical Committees for Human Research of Akita University and Yuri Kumiai General Hospital. The fact that reduction in dose or switching of antipsychotic drugs is a principal management strategy for patients with acute antipsychotic-induced akathisia was explained to all participants during recruitment. Some of the participants were participating in this study after failure of such principal management strategies. Written informed consent was obtained from all subjects, and the research protocol was explained to all participants.

\section{Statistical analyses}

All statistical analyses were performed using PAWS statistics 11.5 (SPSS Japan; Tokyo, Japan). Data are expressed as means \pm SDs. An intention-to-treat analysis including all patients enrolled in the present study was completed. Friedman tests with post hoc analyses were used to examine differences in BARS global akathisia scores and BPRS scores among the different time points. The Wilcoxon single-rank test was used to perform post hoc analysis for the Friedman test, and statistical significance was set at $P<0.016(0.05 /$ number of comparisons $=0.016)$ based on the Bonferroni correction.

\section{Results \\ Samples}

Tables 1 and 2 show the demographic data of the nine subjects. All patients had schizophrenia as defined in the 
Table I Clinical and demographic characteristics

\begin{tabular}{|c|c|c|c|c|c|}
\hline $\begin{array}{l}\text { Age } \\
\text { (years) }\end{array}$ & Sex & $\begin{array}{l}\text { GE dosage } \\
(\mathrm{mg} / \text { day })\end{array}$ & $\begin{array}{l}\text { Causative agent of } \\
\text { akathisia and dosage }\end{array}$ & $\begin{array}{l}\text { Period from akathisia } \\
\text { onset to study (weeks) }\end{array}$ & $\begin{array}{l}\text { Concomitant drug with therapeutic potential } \\
\text { for akathisia }\end{array}$ \\
\hline 42 & $\mathrm{~F}$ & 600 & APZ (30 mg/day) & 2 & Diazepam (15 mg/day) \\
\hline 37 & M & 600 & RIS (6 mg/day) & 3 & Biperiden (2 mg/day) \\
\hline 40 & $\mathrm{~F}$ & 600 & CLZ (600 mg/day) & 2 & Biperiden (I mg/day) and diazepam ( 15 mg/day) \\
\hline 27 & $\mathrm{~F}$ & 600 & APZ (30 mg/day) & 3 & Etizolam (3 mg/day) and bromazepam ( $15 \mathrm{mg} /$ day) \\
\hline 52 & $\mathrm{~F}$ & 300 & PER (40 mg/day) & 4 & $\begin{array}{l}\text { Propranolol ( } 20 \mathrm{mg} / \text { day }) \text {, biperiden }(2 \mathrm{mg} / \text { day }) \text {, } \\
\text { diazepam ( } 4 \mathrm{mg} / \text { day }) \text {, and clonazepam }(0.5 \mathrm{mg} / \text { day })\end{array}$ \\
\hline 20 & $\mathrm{~F}$ & 600 & PAL LAI (I50 mg/4 weeks) & 1 & None \\
\hline 44 & $\mathrm{~F}$ & 600 & APZ LAI (400 mg/4 weeks) & 2 & None \\
\hline 55 & M & 600 & APZ (6 mg/day) & 3 & None \\
\hline 37 & $\mathrm{~F}$ & 600 & APZ (24 mg/day) & 2 & Diazepam (4 mg/day) \\
\hline
\end{tabular}

Abbreviations: APZ, aripiprazole; CLZ, clozapine; F, female; GE, gabapentin enacarbil; LAI, long-acting injection; M, male; PAL, paliperidone; PER, perospirone; RIS, risperidone.

DSM-5. One patient declined to continue this study on the third day after the start of the study because the patient wanted to be treated using some other strategy. Therefore, eight patients thus completed the study (male: 2, female 6, age: $38.8 \pm 11.6$ years). The average dosage of GE was $567 \mathrm{mg} /$ day (300 mg/day $[\mathrm{n}=1], 600 \mathrm{mg} /$ day $[\mathrm{n}=8])$. The drugs that caused akathisia were aripiprazole $(n=5)$, risperidone $(n=1)$, paliperidone $(n=1), \operatorname{CLZ}(n=1)$, and perospirone $(n=1)$. From the onset of akathisia to the end of the study, the patients did not take any of the following drugs, which may be considered therapeutic agents for akathisia: propranolol, ${ }^{20,21}$ mirtazapine, ${ }^{22,23}$ mianserin, ${ }^{22}$ trazodone, ${ }^{24}$ cyproheptadine, ${ }^{25,26}$ zolmitriptan, ${ }^{27}$ clonidine,${ }^{28}$ dopamine agonists,${ }^{28}$ and vitamin B6 supplement. ${ }^{29}$ MT evaluated all the patients.

\section{Primary outcome}

Figure 1 shows the changes in the BARS global akathisia score. The mean $\pm \mathrm{SD}$ of BARS global scores at baseline and the endpoint is $3.3 \pm 0.5$ and $1.1 \pm 1.3$, respectively. The result of the Friedman's test was highly significant $(P=0.0005)$. Therefore, post hoc analyses were performed

Table 2 Changes in symptom evaluation scores during the study

\begin{tabular}{l|l|l|l|l|l|l}
\hline Case & \multicolumn{3}{l|}{$\begin{array}{l}\text { BARS global akathisia } \\
\text { score }\end{array}$} & \multicolumn{3}{l}{ BPRS score } \\
\cline { 2 - 7 } & 0 week & I week & 2 weeks & 0 week & I week & 2 weeks \\
\hline 1 & 3 & I & I & 4 I & 34 & 32 \\
2 & 3 & 2 & 1 & 47 & 47 & 47 \\
3 & 3 & 2 & 2 & 46 & 35 & 35 \\
4 & 3 & 2 & 1 & 48 & 48 & 46 \\
5 & 4 & 2 & 0 & 39 & 37 & 37 \\
6 & 3 & 2 & 1 & 34 & 33 & 32 \\
7 & 4 & 4 & 4 & 31 & 31 & 31 \\
8 & 4 & 1 & 0 & 38 & 38 & 38 \\
9 & 3 & 1 & 0 & 40 & 38 & 38 \\
\hline
\end{tabular}

Abbreviations: BARS, Barnes Akathisia Rating Scale; BPRS, Brief Psychiatric Rating Scale. using the Wilcoxon signed-rank test. The BARS global akathisia score was significantly decreased after 1 and 2 weeks of treatment compared with baseline $(P=0.01$ and $P=0.01$, respectively). There was no significant difference in the BARS global akathisia score between week 1 and week 2 .

\section{Secondary outcome}

Figure 2 illustrates the change in the BPRS score. The result of the Friedman's test was significant $(P=0.0058)$. Therefore, post hoc analyses were performed. There were no significant differences in BPRS scores in the post hoc analyses. The mean \pm SD of the BARS Objective akathisia score was $1.9 \pm 0.8$ at week $0,0.3 \pm 1.0$ at week 1 , and $0.3 \pm 1.0$ at week 2 . The mean $\pm \mathrm{SD}$ of the BARS Subjective akathisia

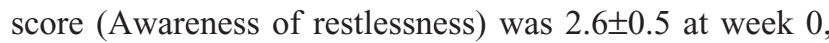
$1.8 \pm 0.7$ at week 1 , and $1.0 \pm 1.0$ at week 2 . The mean \pm SD of the BARS Subjective akathisia score (Distress related to restlessness) was $2.3 \pm 0.5$ at week $0,1.3 \pm 0.7$ at week 1 , and $0.9 \pm 0.9$ at week 2 .

\section{Adverse events}

No serious adverse events due to GE administration occurred. Mild somnolence was observed in one patient and dry mouth in another.

\section{Discussion}

This is the first study to investigate the effectiveness of GE for akathisia. The present findings suggest that GE significantly improves the severity of akathisia within 2 weeks. Based on the results, GE may be a candidate therapeutic agent for akathisia. The akathisia treatment described in Maudsley's guideline does not improve all cases of akathisia. ${ }^{7}$ It is, therefore, difficult to state that akathisia treatment is well established. GE may be a new treatment option for patients 


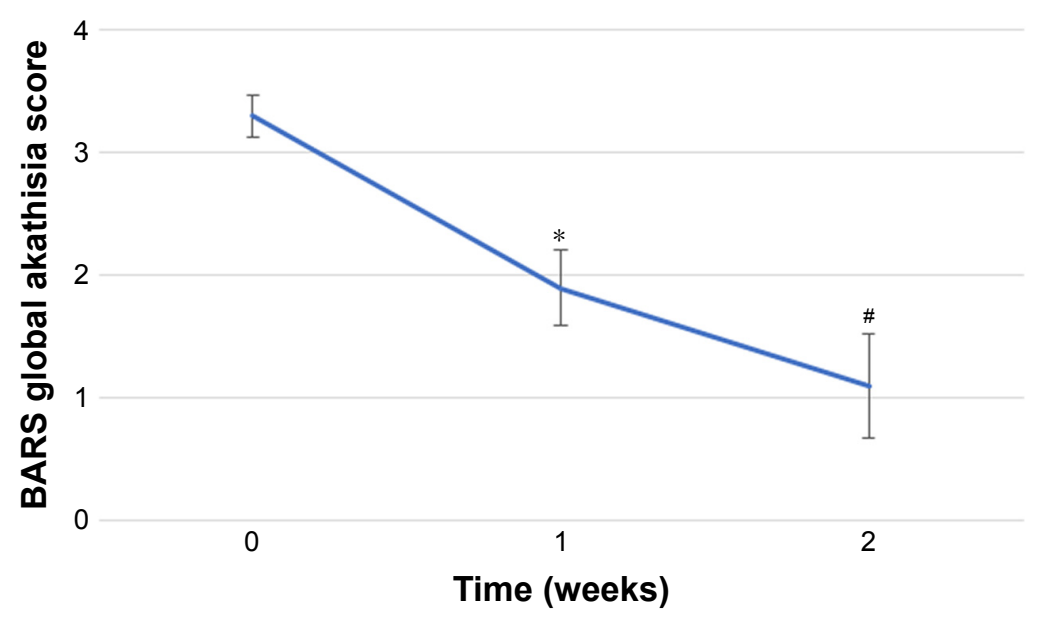

Figure I Changes in the BARS global akathisia score.

Notes: Compared with BARS global akathisia score at the baseline, global akathisia score at week I and 2 significantly decreased $(P=0.0 \mathrm{I}, P=0.0 \mathrm{I}$, respectively). Between the BARS global akathisia scores at week I and 2, significant difference was not observed. Error bars indicate standard error. *Significant difference between baseline and I week after treatment onset $(P<0.016)$. "Significant difference between baseline and 2 weeks after treatment onset $(P<0.016)$.

Abbreviation: BARS, Barnes Akathisia Rating Scale.

with akathisia, particularly cases wherein it is difficult to simply reduce the dosage of antipsychotics or withdraw antipsychotic treatment.

The mechanism by which GE improves akathisia is still unclear. Reduced central GABA-ergic activity is suggested as a pathogenic mechanism for akathisia. ${ }^{13}$ In fact, gabapentin has a structure similar to that of the neurotransmitter GABA and increases GABA activity by inhibiting certain calcium channels. ${ }^{14,15}$ Because GE is a prodrug of gabapentin, it may have exerted the effects observed here through the GABA neurotransmitter system.

Safety is important in medicinal therapies for akathisia. The only contraindications for GE are advanced renal dysfunction and a history of anaphylaxis due to GE. GE has been reported to be safe even after long-term administration. ${ }^{30,31}$ Propranolol, which is widely used for the treatment of akathisia, sometimes cannot be used in patients with conditions, such as asthma, bradycardia, and hypotension. ${ }^{8}$ While mirtazapine and mianserin are therapeutic agents for akathisia, they may cause akathisia on their own, and care must be taken when treating patients with akathisia using such medications. ${ }^{32,33}$ In some cases, anticholinergic drugs cannot be used for treatment of akathisia due to side effects such as ileus, urinary disorders, and elevated intraocular pressure. In addition, anticholinergic drugs lead to tardive dyskinesia after long-term administration. ${ }^{34}$

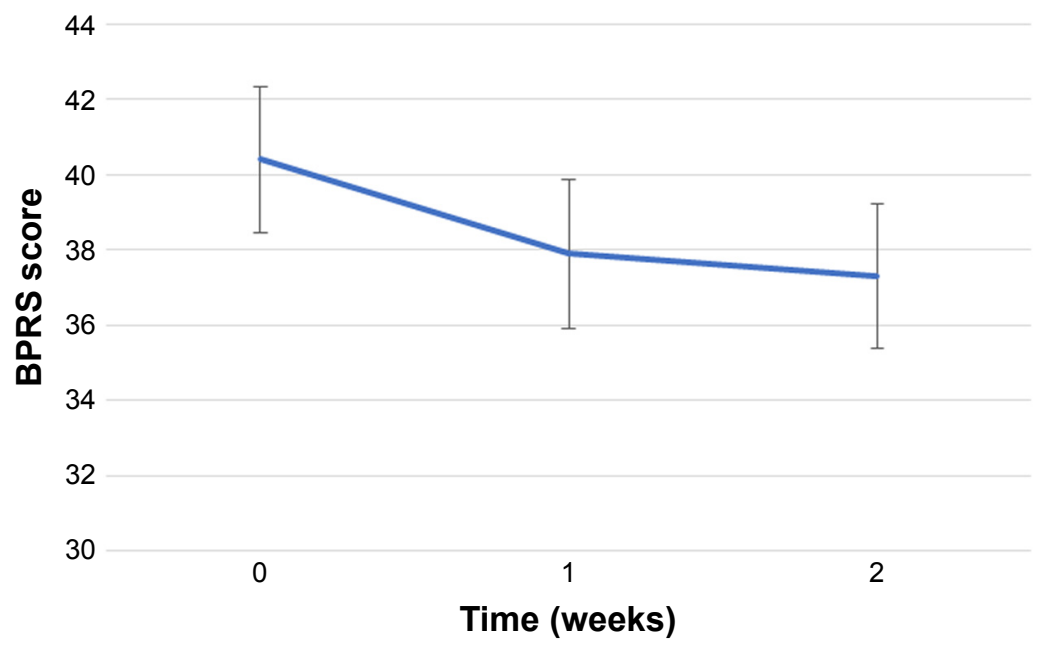

Figure 2 Changes in BPRS scores.

Notes: Any significant difference was not found on BPRS scores in post hoc analyses. Error bars indicate standard error. Abbreviation: BPRS, Brief Psychiatric Rating Scale. 
This study has some limitations. First, a blinded, placebo control group was not examined. It was thus unclear whether the improvement in the BARS global akathisia score was a consequence of GE administration. Second, the sample size was small. Because this study began as a pilot study, we minimized recruitment for this study. Third, gender bias may also be considered one of limitation. The subject of this study was a group with a strong gender bias. However, no research has been published to indicate sex differences in the action of gabapentin. Therefore, the possibility that the gender bias in this study population affected the research results would be minimal. Fourth, the study period was probably short. Fifth, a concomitant drug with therapeutic potential for akathisia used in some participants might have influenced the study findings. These limitations should be considered in further research involving more time and a large sample size.

\section{Conclusion}

GE has a therapeutic potential for antipsychotics-induced akathisia. Future trials with well-established study designs are warranted to examine the effectiveness of GE for akathisia.

\section{Abbreviations}

BARS, Barnes Akathisia Rating Scale; BPRS, Brief Psychiatric Rating Scale; CLZ, clozapine; DSM-5, Diagnostic and Statistical Manual of Mental Disorders, Fifth Edition; GABA, $\gamma$-aminobutyric acid; GE, Gabapentin enacarbil.

\section{Acknowledgment}

We thank Editage (www.editage.jp) for English language editing.

\section{Author contributions}

All authors contributed to data analysis, drafting and revising the article, gave final approval of the version to be published, and agree to be accountable for all aspects of the work.

\section{Disclosure}

MT has received speaker's honoraria from Mitsubishi Tanabe Pharma Corporation, Otsuka Pharmaceutical, Sumitomo Dainippon Pharma, Daiichi Sankyo Company, and Eisai. TK has received speaker's honoraria from Otsuka Pharmaceutical, MSD, and Eisai. TS has received research grants from Eisai and MSD, and speaker's honoraria from MSD, Takeda Pharmaceuticals, Pfizer, and Yoshitomi Pharmaceuticals. The authors report no other conflicts of interest in this work.

\section{References}

1. Poyurovsky M. Acute antipsychotic-induced akathisia revisited. Br J Psychiatry. 2010;196(2):89-91.

2. Cem Atbaşoglu E, Schultz SK, Andreasen NC. The relationship of akathisia with suicidality and depersonalization among patients with schizophrenia. J Neuropsychiatry Clin Neurosci. 2001;13(3):336-341.

3. Duncan EJ, Adler LA, Stephanides M, Sanfilipo M, Angrist B. Akathisia and exacerbation of psychopathology: a preliminary report. Clin Neuropharmacol. 2000;23(3):169-173.

4. Pra M, van Putten T, Yale C, et al. Predicting individual responses to drug treatment in schizophrenia. J Nerv Ment Dis. 1976;125(3):177-183.

5. van Putten T. Why do schizophrenic patients refuse to take their drugs? Arch Gen Psychiatry. 1974;31(1):67-72.

6. Lee YW, Kim JH, Ann JH, et al. Subjective well-being in patients with schizophrenia treated with atypical antipsychotics: the impact of psychopathology and adverse drug effects. Clin Psychopharmacol Neurosci. 2010;8(3):149-155.

7. Taylor D, Paton C, Kapur S. The Maudsley Prescribing Guidelines in Psychiatry. 12th ed. West Sussex: John Willey \& Sons; 2015:88-89.

8. Poyurovsky M, Pashinian A, Weizman R, Fuchs C, Weizman A. Lowdose mirtazapine: a new option in the treatment of antipsychotic-induced akathisia. A randomized, double-blind, placebo- and propranololcontrolled trial. Biol Psychiatry. 2006;59(11):1071-1077.

9. Chen YH, Lee HC, Lin HC. Prevalence and risk of atopic disorders among schizophrenia patients: a nationwide population based study. Schizophr Res. 2009;108(1-3):191-196.

10. Pfeffer G, Chouinard G, Margolese HC. Gabapentin in the treatment of antipsychotic-induced akathisia in schizophrenia. Int Clin Psychopharmacol. 2005;20(3):179-181.

11. Sullivan MA, Wilbur R. Gabapentin pharmacotherapy for antipsychoticinduced akathisia: single-patient experiment and case report. Ther $A d v$ Psychopharmacol. 2014;4(2):100-102.

12. Takeshima M, Ishikawa H, Kikuchi Y, Kanbayashi T, Shimizu T. Successful management of clozapine-induced akathisia with gabapentin enacarbil: a case report. Clin Psychopharmacol Neurosci. 2018; 16(3):346-348.

13. Lima AR, Soares-Weiser K, Bacaltchuk J, Barnes TR. Benzodiazepines for neuroleptic-induced acute akathisia. Cochrane Database Syst Rev. 2002;(1):CD001950.

14. Garcia-Borreguero D, Larrosa O, de La Llave Y, Verger K, Masramon X, Hernandez G. Treatment of restless legs syndrome with gabapentin: a double-blind, cross-over study. Neurology. 2002;59(10): 1573-1579.

15. Maneuf YP, Gonzalez MI, Sutton KS, Chung FZ, Pinnock RD, Lee K. Cellular and molecular action of the putative GABA-mimetic, gabapentin. Cell Mol Life Sci. 2003;60(4):742-750.

16. American Psychiatric Association. Diagnostic and Statistical Manual of Mental Disorders. 5th ed. Virginia: American Psychiatric Publishing; 2013.

17. Barnes TR. A rating scale for drug-induced akathisia. Br J Psychiatry. 1989;154:672-676.

18. Overall JE, Gorman DR. The Brief Psychiatric Rating Scale. Psychol Rep. 1962;10(3):799-812.

19. Astellas Pharma Inc. Regnite ${ }^{\circledR}$ Tablets $300 \mathrm{mg}$ Interview Form, 7th version. Tokyo: 2018. Available from: https://amn.astellas.jp/jp/di/list/ reg/pi_reg.pdf. Accessed November 14, 2018. Japanese.

20. Adler L, Angrist B, Peselow E, Corwin J, Maslansky R, Rotrosen J. A controlled assessment of propranolol in the treatment of neurolepticinduced akathisia. Br J Psychiatry. 1986;149:42-45.

21. Kramer MS, Gorkin RA, Dijohnson C, Sheves P. Propranolol in the treatment of neuroleptic-induced akathisia (NIA) in schizophrenics: a double-blind, placebo-controlled study. Biol Psychiatry. 1988;24(7): 823-827.

22. Laoutidis ZG, Luckhaus C. 5-HT2A receptor antagonists for the treatment of neuroleptic-induced akathisia: a systematic review and meta-analysis. Int J Neuropsychopharmacol. 2014;17(5):823-832. 
23. Poyurovsky M, Weizman R, Weizman A. Mirtazapine - a multifunctional drug: low dose for akathisia. CNS Spectr. 2011;16(2):63.

24. Stryjer R, Rosenzcwaig S, Bar F, Ulman AM, Weizman A, Spivak B. Trazodone for the treatment of neuroleptic-induced acute akathisia: a placebo-controlled, double-blind, crossover study. Clin Neuropharmacol. 2010;33(5):219-222.

25. Weiss D, Aizenberg D, Hermesh H, et al. Cyproheptadine treatment in neuroleptic-induced akathisia. Br J Psychiatry. 1995;167(4): 483-486.

26. Fischel T, Hermesh H, Aizenberg D, et al. Cyproheptadine versus propranolol for the treatment of acute neuroleptic-induced akathisia: a comparative double-blind study. J Clin Psychopharmacol. 2001;21(6):612-615.

27. Avital A, Gross-Isseroff R, Stryjer R, Hermesh H, Weizman A, Shiloh R. Zolmitriptan compared to propranolol in the treatment of acute neuroleptic-induced akathisia: a comparative double-blind study. Eur Neuropsychopharmacol. 2009;19(7):476-482.

28. Miller CH, Fleischhacker WW. Managing antipsychotic-induced acute and chronic akathisia. Drug Saf. 2000;22(1):73-81.
29. Miodownik C, Lerner V, Statsenko N, et al. Vitamin B6 versus mianserin and placebo in acute neuroleptic-induced akathisia: a randomized, double-blind, controlled study. Clin Neuropharmacol. 2006; 29(2):68-72.

30. Inoue Y, Uchimura N, Kuroda K, Hirata K, Hattori N. Long-term efficacy and safety of gabapentin enacarbil in Japanese restless legs syndrome patients. Prog Neuropsychopharmacol Biol Psychiatry. 2012;36(2):251-257.

31. Ellenbogen AL, Thein SG, Winslow DH, et al. A 52-week study of gabapentin enacarbil in restless legs syndrome. Clin Neuropharmacol. 2011;34(1):8-16.

32. Gulsun M, Doruk A. Mirtazapine-induced akathisia. J Clin Psychopharmacol. 2008;28(4):467.

33. Aggarwal A, Khandelwal A, Garg A, Jiloha RC. Akathisia associated with mianserin. J Clin Psychopharmacol. 2010;30(3):338-339.

34. Ogino S, Miyamoto S, Miyake N, Yamaguchi N. Benefits and limits of anticholinergic use in schizophrenia: focusing on its effect on cognitive function. Psychiatry Clin Neurosci. 2014;68(1):37-49.

\section{Publish your work in this journal}

Neuropsychiatric Disease and Treatment is an international, peerreviewed journal of clinical therapeutics and pharmacology focusing on concise rapid reporting of clinical or pre-clinical studies on a range of neuropsychiatric and neurological disorders. This journal is indexed on PubMed Central, the 'PsycINFO' database and CAS, and is the official journal of The International Neuropsychiatric Association (INA). The manuscript management system is completely online and includes a very quick and fair peer-review system, which is all easy to use. Visit http://www.dovepress.com/testimonials.php to read real quotes from published authors. 